\title{
الأدب العربي بين الفن و البمال
}

\section{Arabic literature between art and beauty}

\author{
إعـآ \\ حسين عبد النافع أبانكـاندا \\ Doi:10.12816/jnal.2021.144693
}

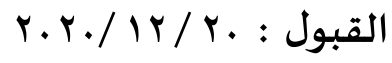

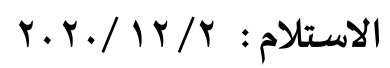

المستَخلص : الاسم:

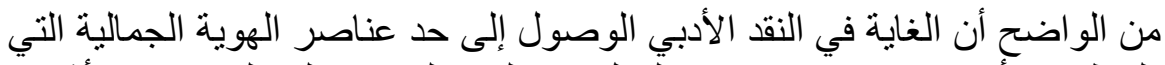

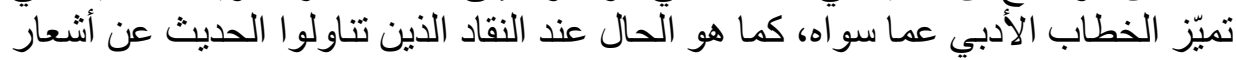

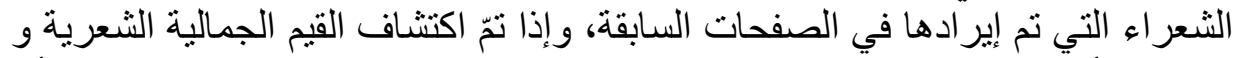

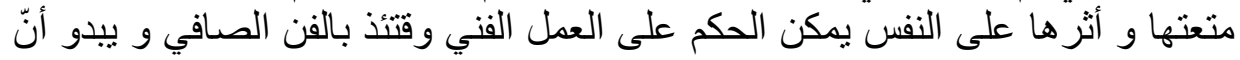

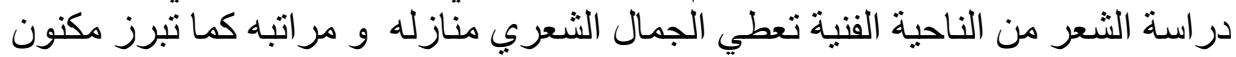

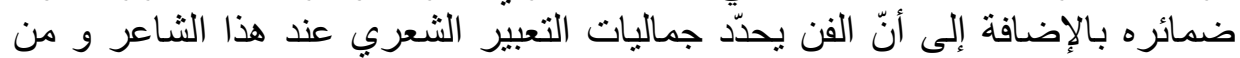

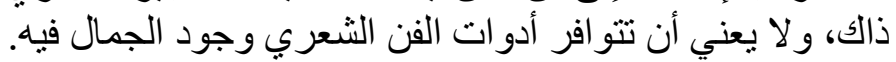

\section{Abstract:}

It is clear that the purpose of literary criticism is to reach the limit of the aesthetic identity elements that distinguish the literary discourse from others, as is the case with the critics who dealt with the discussion of the poems of the poets that were mentioned in the previous pages, and if the aesthetic values of poetry and their enjoyment and their impact on the soul were discovered The artistic work at that time can be judged by pure art, and it seems that the study of poetry from the technical point of view gives poetic beauty its homes and ranks, as well as the content of his conscience, in addition to that art defines the aesthetics of poetic expression for this poet and from that, and does not mean that the tools of poetic art are available and the presence of beauty in it. 


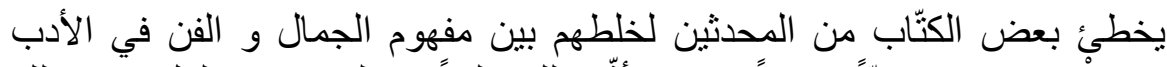

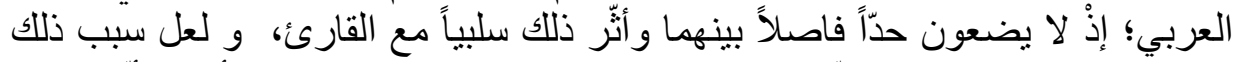

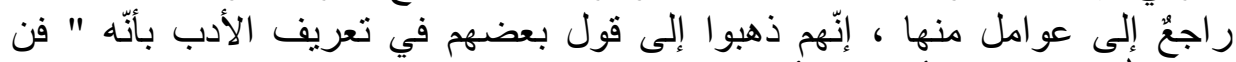

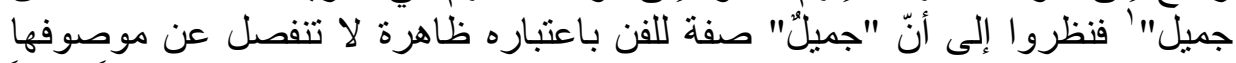
(الفن) حسب موقعه في الإعراب كما جاء في التعريف السابق فعدّو الجمال جز عاء لازماً

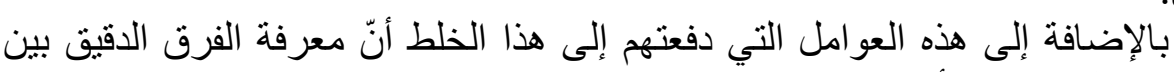

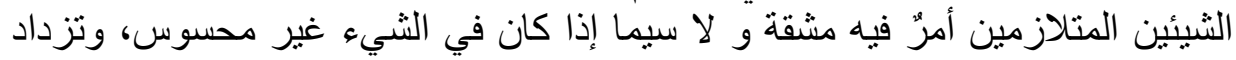

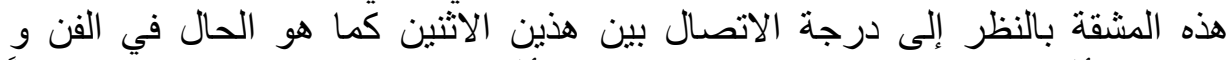

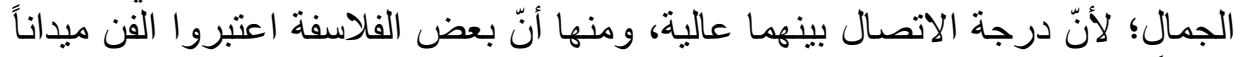

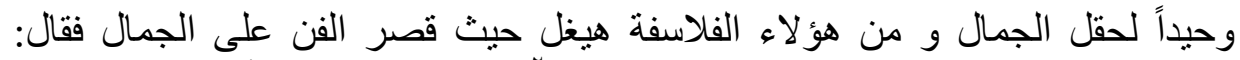

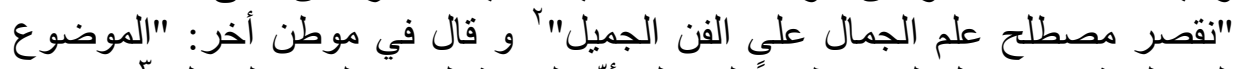

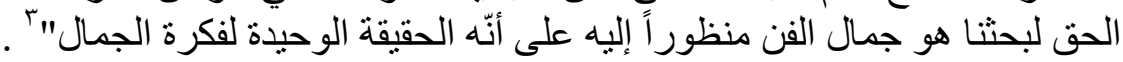

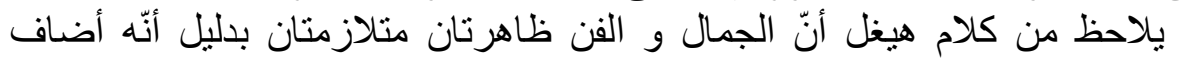

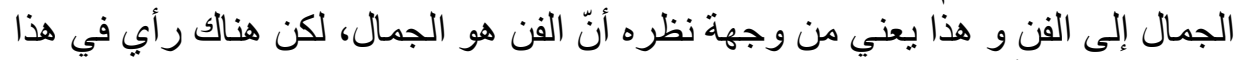

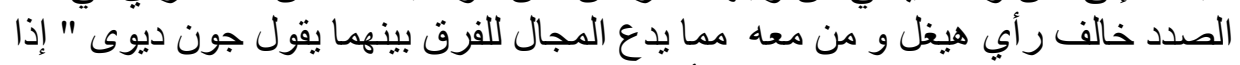

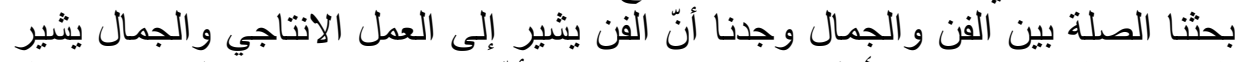

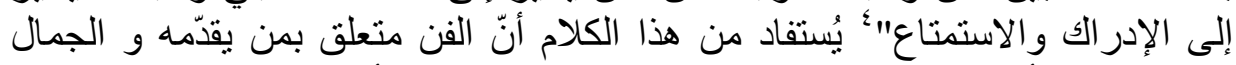

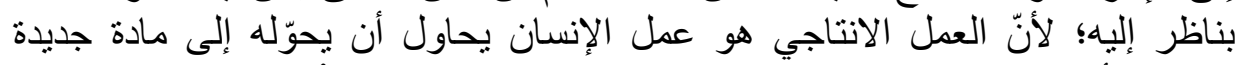

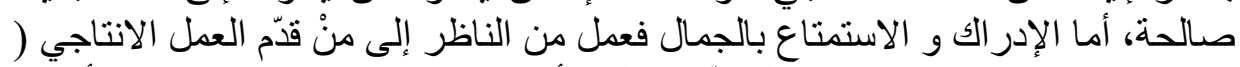

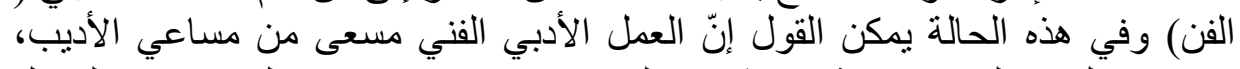

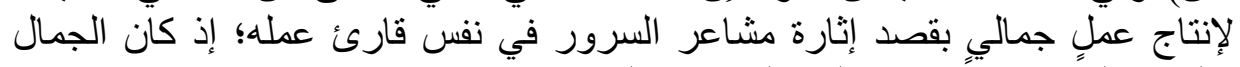

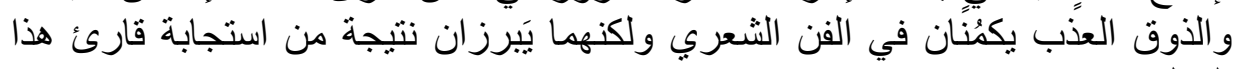

النموذج على التمييز بين العمل الفتّي والجمالي.

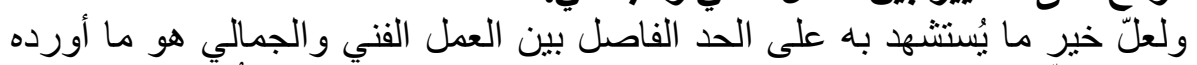

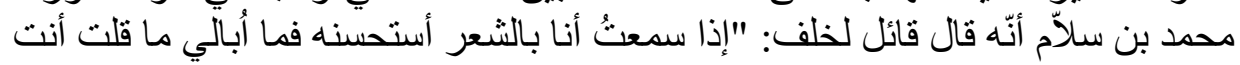

أبو عبد الرحمن ابن عقيل الظاهري، مبادئ في نظرية الثعر والجمال، ص. صائ

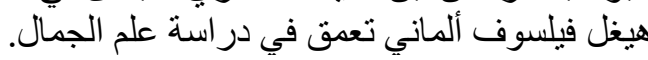

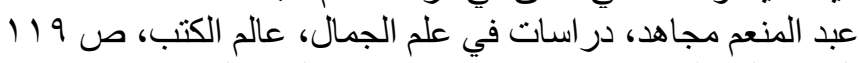

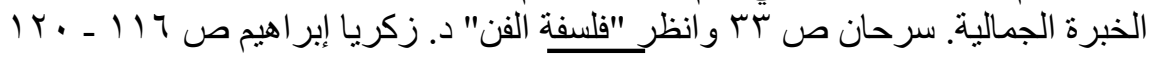




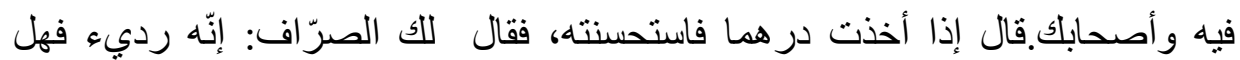

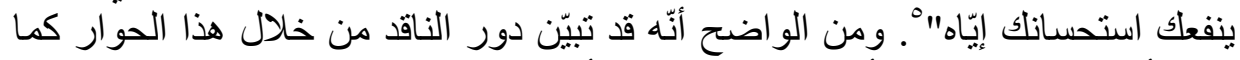

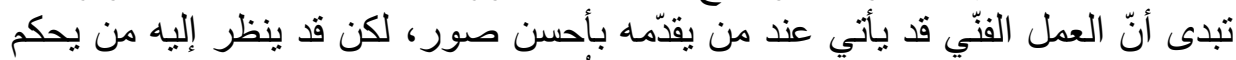

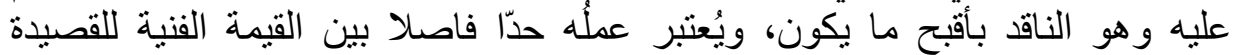

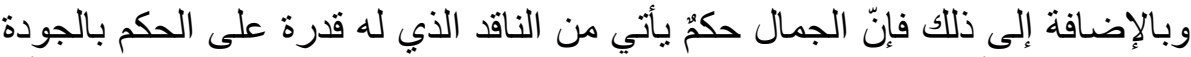
وخلافها.

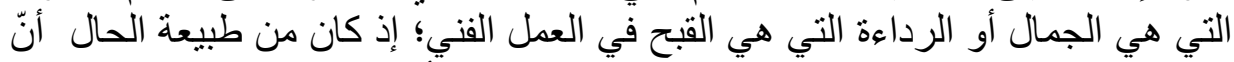

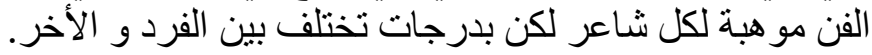

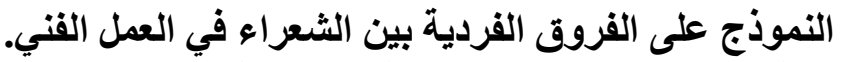

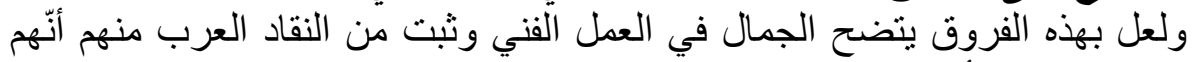

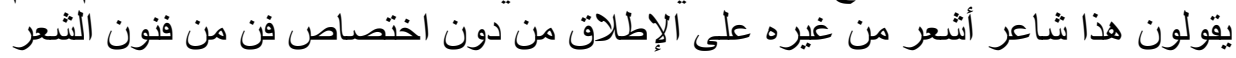

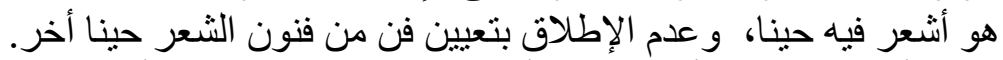

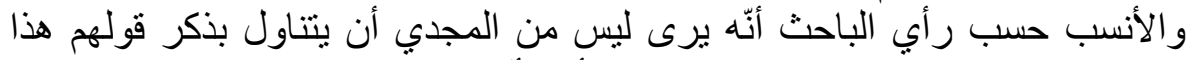

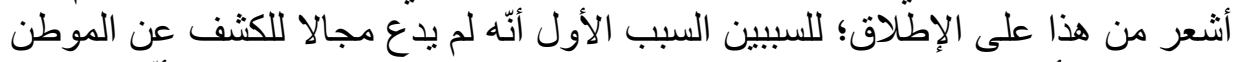

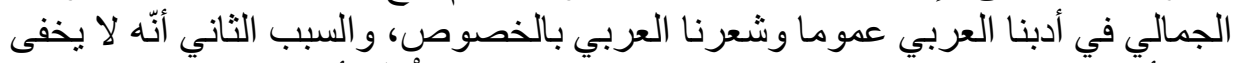

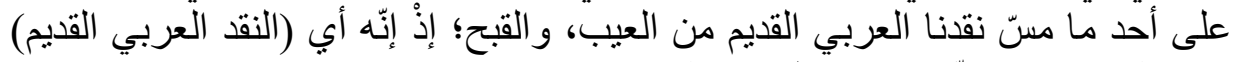

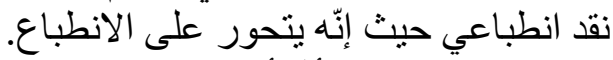

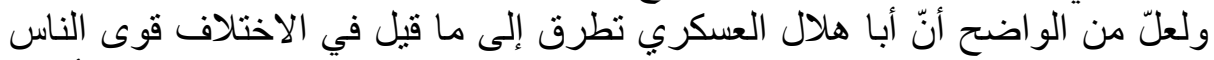

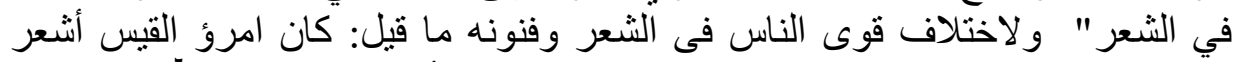

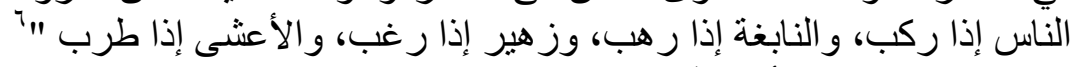

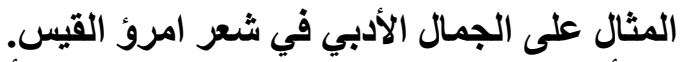

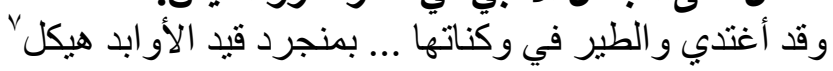

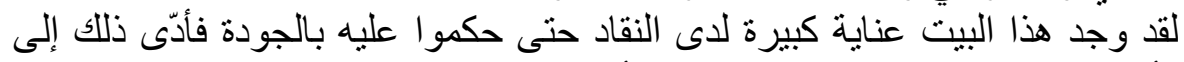

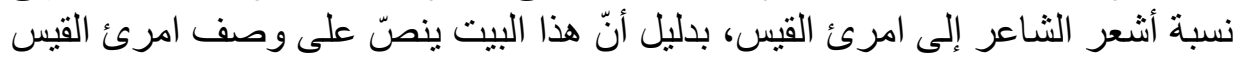

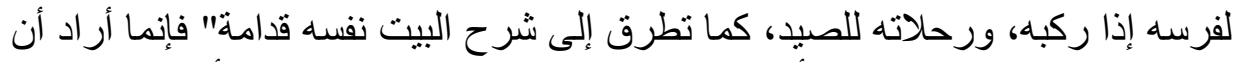

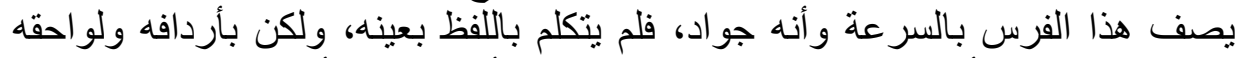

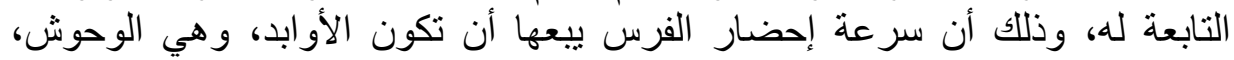

• محمد بن سلاّم الجمعي، طبقان فحول الشعر اء، ت/ محمود محمد شاكر، دار المدني

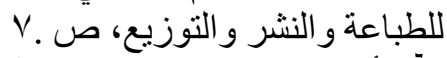

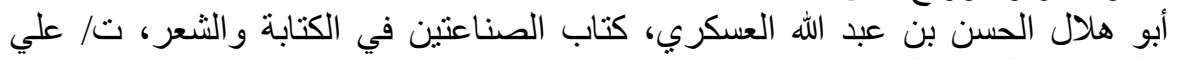

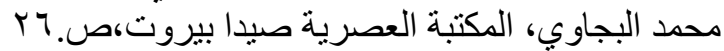

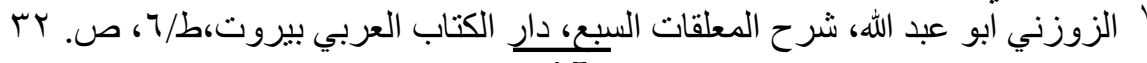


كالمقيدة له إذا نحا في طلبها والناس يستجيدون لامرئ القيس هذه اللفظة، فيقولون: هو إنها

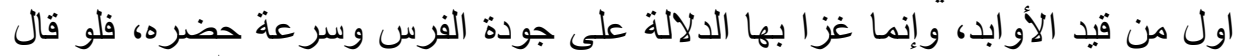

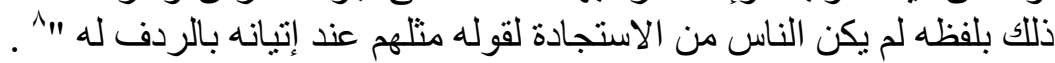

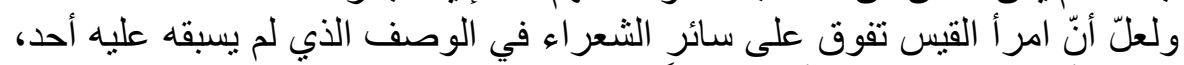

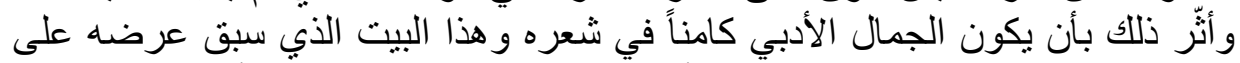

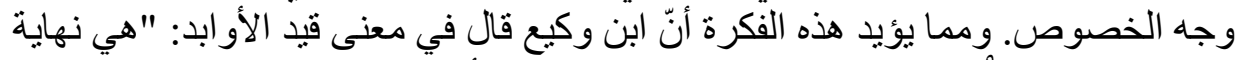

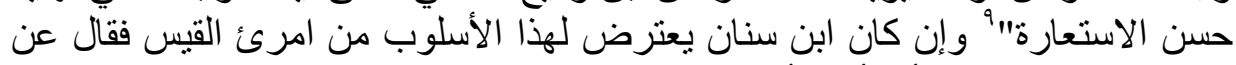

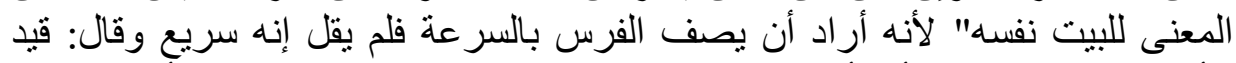

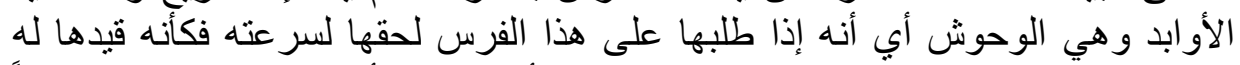

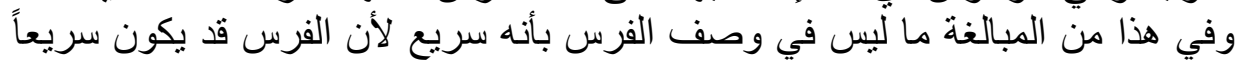

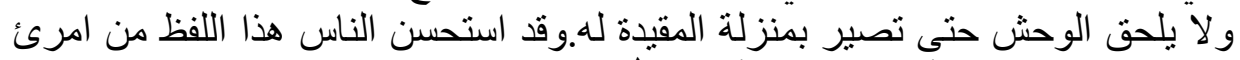

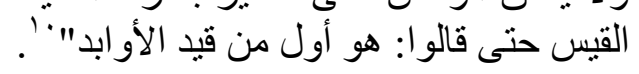

ومما يدل على عدم موافقة ابن سنان على أسلوب امرئ القيس قوله: وفي هذا من

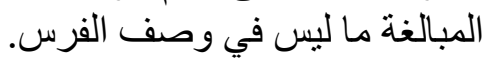

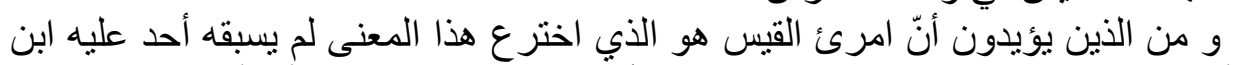

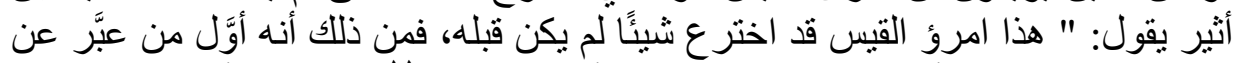

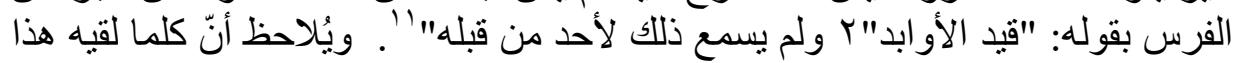

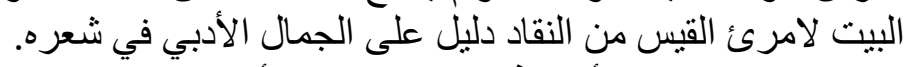

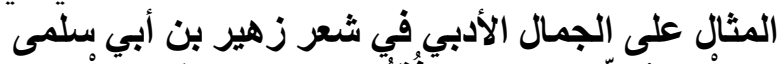

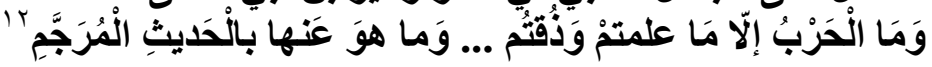

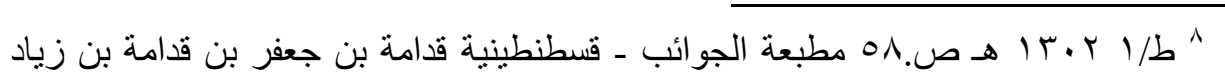

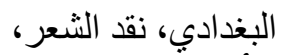

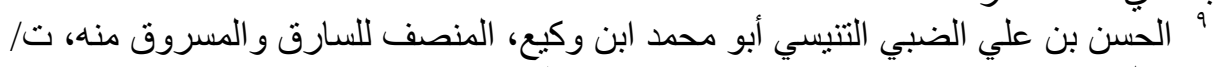

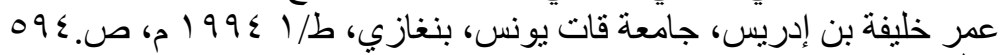

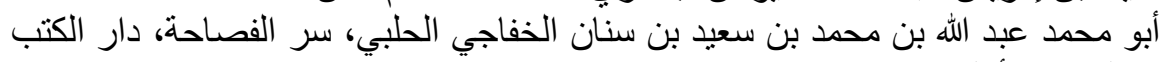

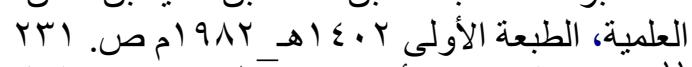

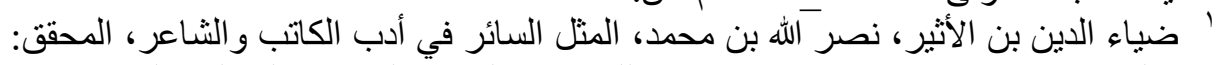

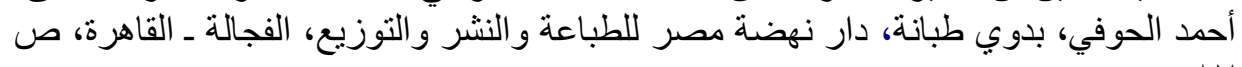

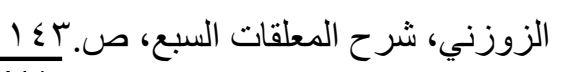




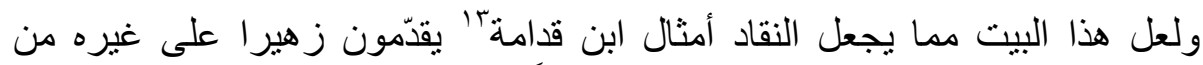

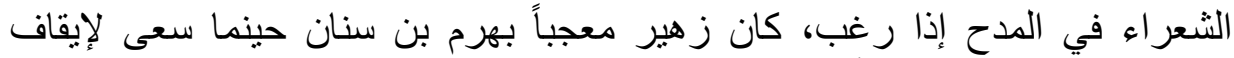

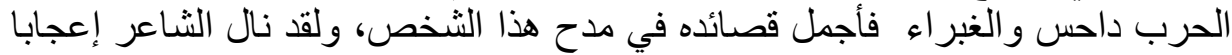

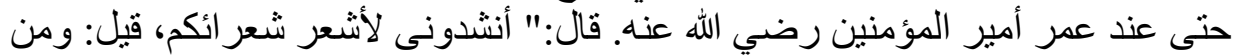

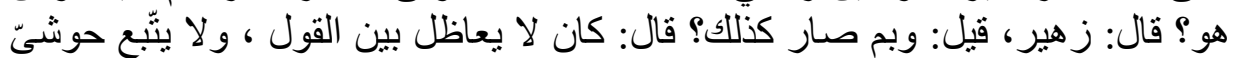

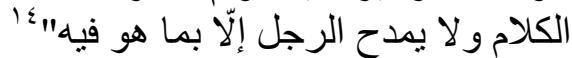

ولا قرار على زأر مـن الأسد علدي

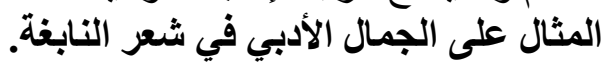

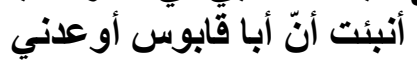

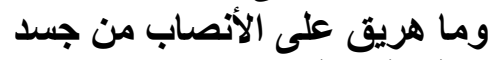

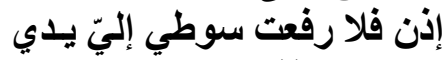

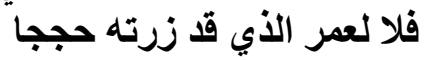

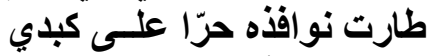

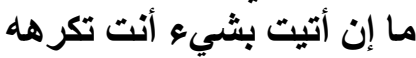

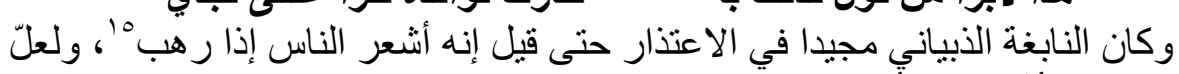

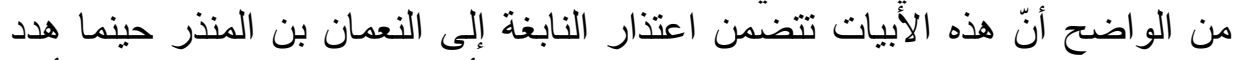

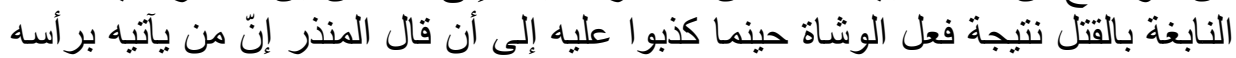

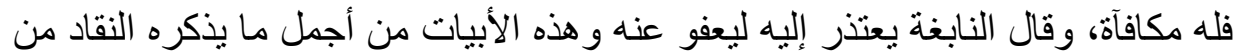
الأربيات للاعتذار. المثال على الجمال الأدبي في شُعر الأعثى قيس.

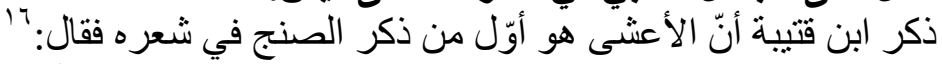

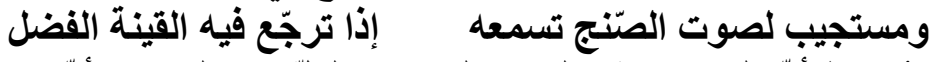

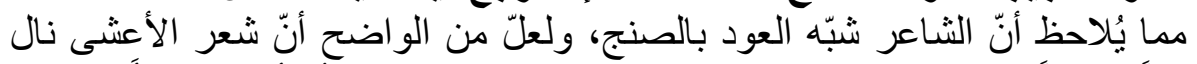

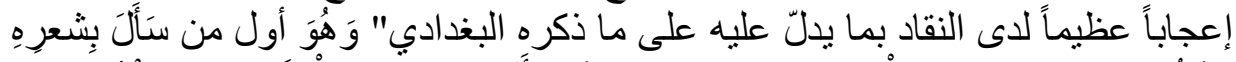

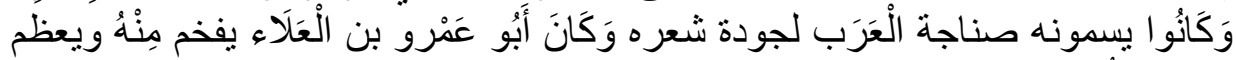

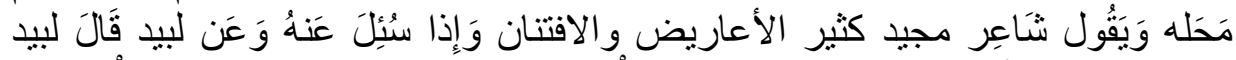

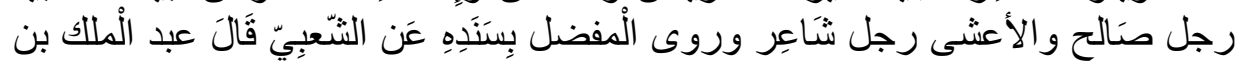

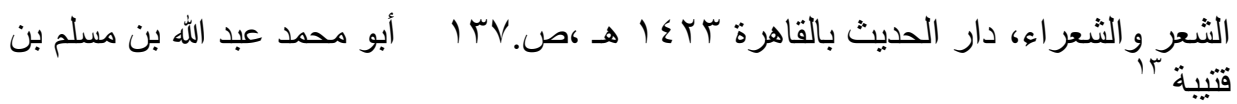
المكان نفسه 1 أبية "محمد بن الحسن بن محمد بن علي بن حمدون، التذكرة الحمدونية، دار صادر، بيروت، ط/ ا إئ

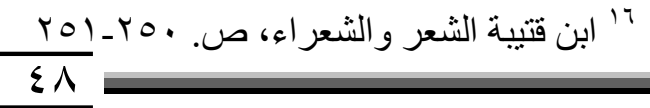




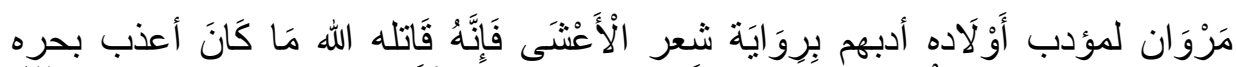

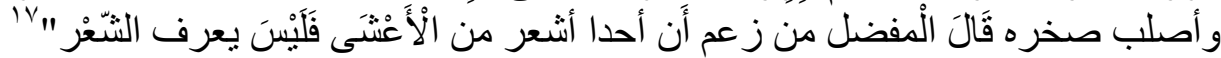

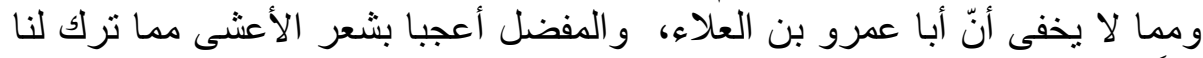

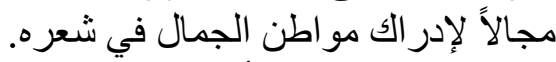

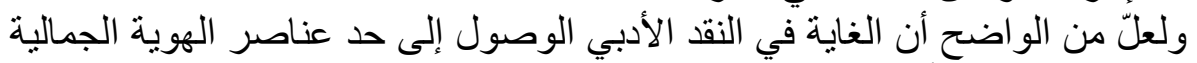

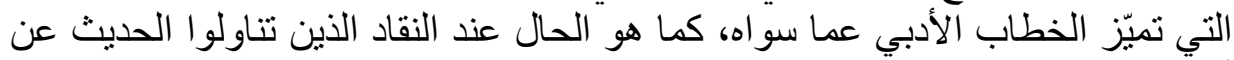

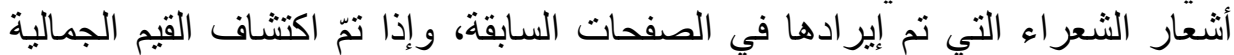

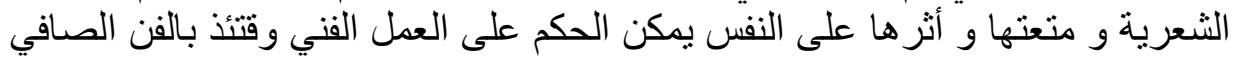

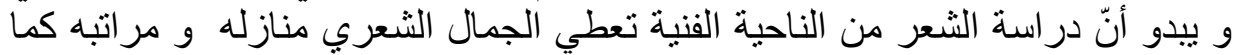

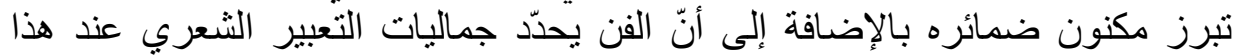

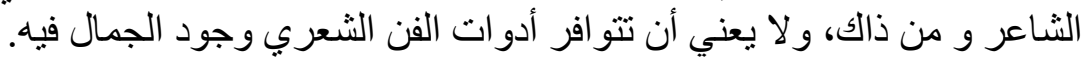

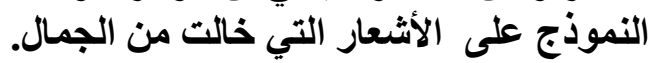

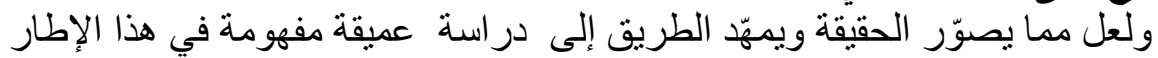

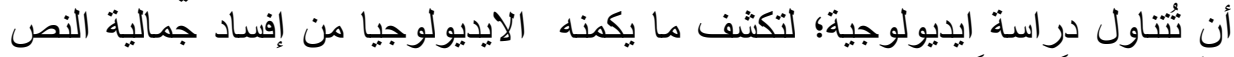
الأدبي شعر آ ونثراً. الايديلوجيا.

ولعل من الواضح أنّ لايديولوجيا أثرا سلبيا على الثّر العربي، فيؤدي هذا الأثر

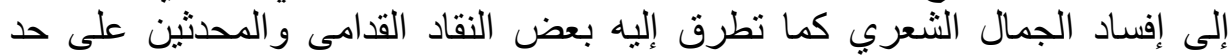

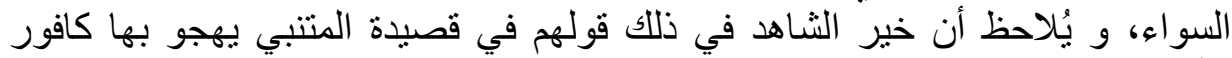

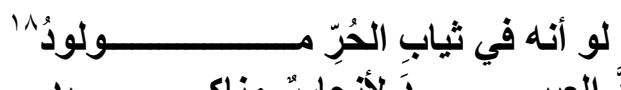

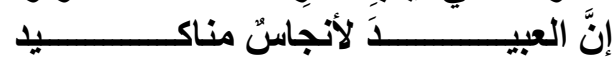

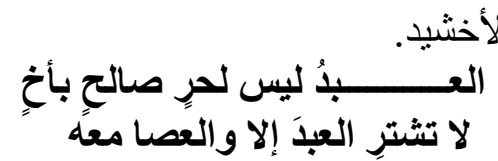

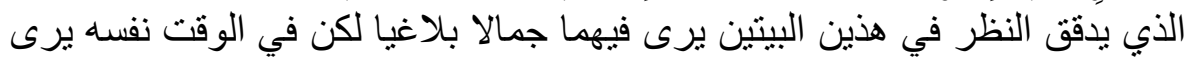

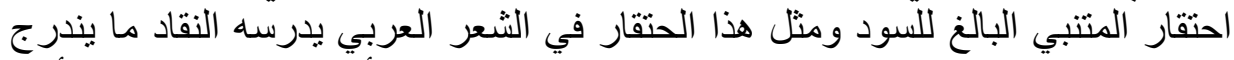

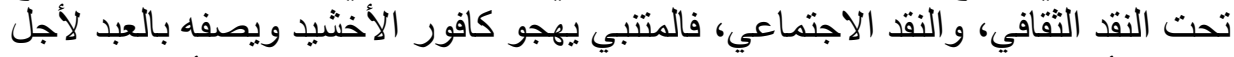

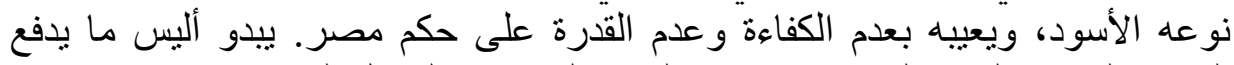

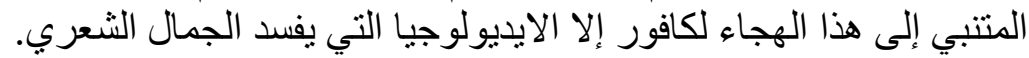

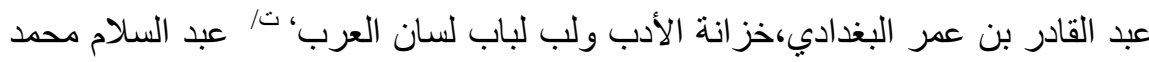

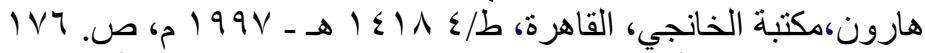

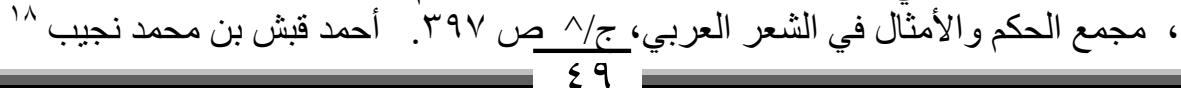




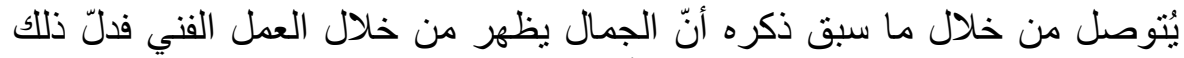

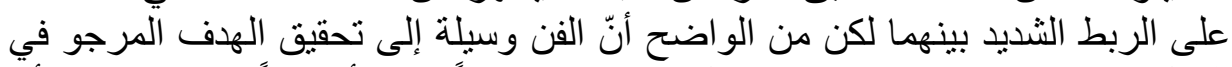

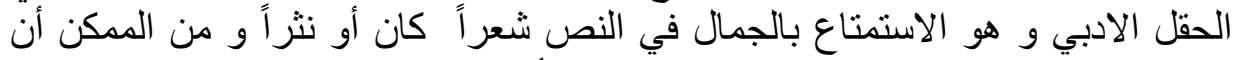

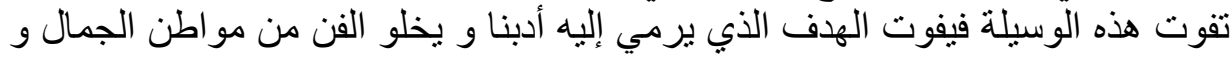

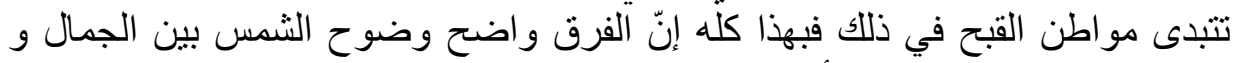

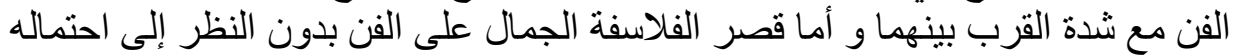

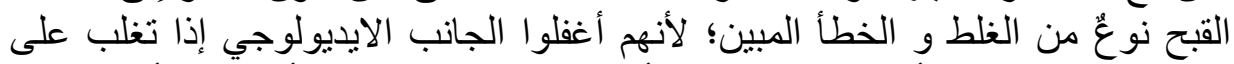

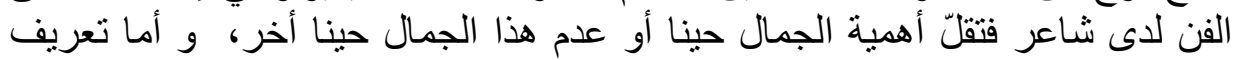

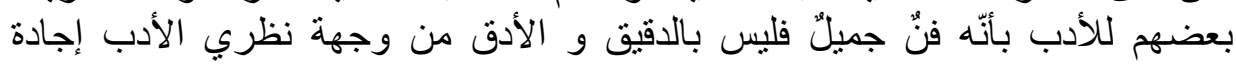
التعبير. 
أبو عبد الرحمن ابن عقيل الظاهري، مبادئ في نظرية الثعر و الجمال.

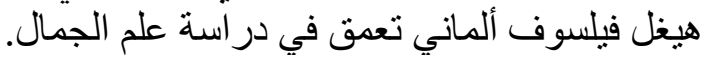

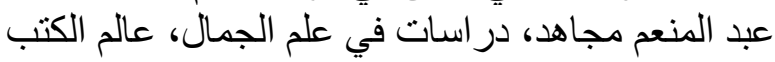

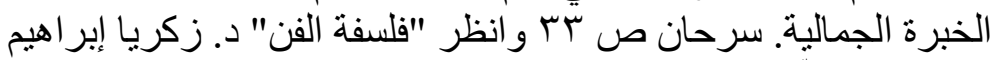

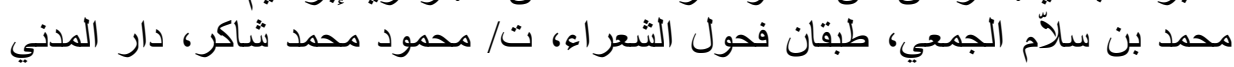

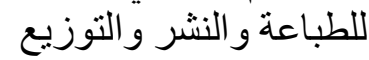

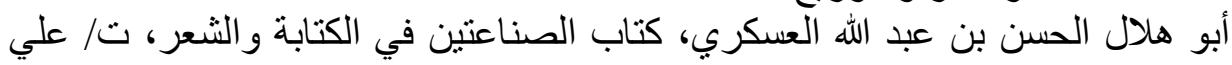

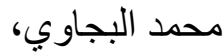

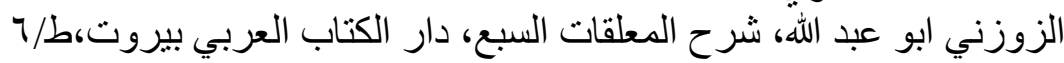

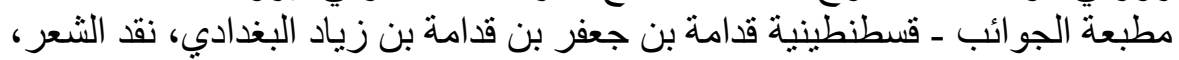

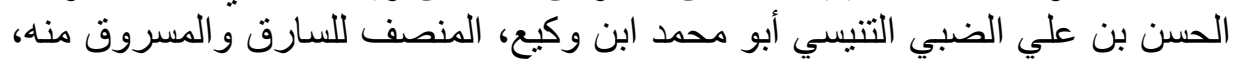

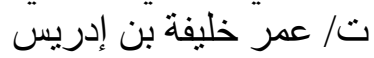
أبو محمد عبد الله بن محمد بن سعيد بإنبن بن سنان الخفاجي الحلبي، سر الفصاحة، دار الكتب

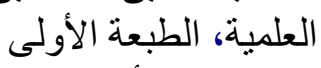
ضياء الدين بن الأثير، نصر الألى الله بن محمد، المثل السائر في أدب الكاتب والثاعر،

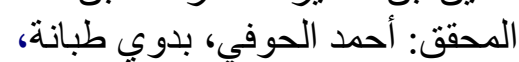
محمد بن الحسن بن محمد بن علي بن حمدون، التذكرة الحمدونية، دار صادر، بليروت، بيروت ط عبد القادر بن عمر البغدادي،خزانة الأدب ولب لباب لسان العرب، تالعبد السلام محمد

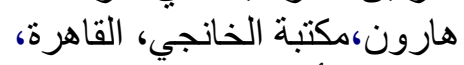

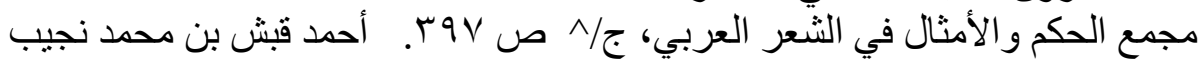


